\title{
An Information Technology Based Instructional Model for Effective Learning
}

\author{
Dr. Ali Hussain Higgi
}

Zayed University

\begin{abstract}
This paper presents an information technology based instructional model for effective learning in management information systems programs and modules for students in undergraduate education. This model is primarily centered on the traditional in-class learning model. Information technology is used in a unique and novel way in order to create a learning environment which not only engages students in the learning process but also enhances their problems solving skills, analysis and decision making abilities. The model embeds information technology in projects in order to hide complexities but without compromising achievement of learning objectives. It also uses information technology in a simulation mode in order to demonstrate key concepts or learning themes, to simulate main themes presented in case studies and to simulate problems behaviors. The model employs other creative techniques in order to deliver its overall goals.
\end{abstract}

\section{Introduction}

This paper starts by presenting a review of the relevant literatures and various learning models. This is followed by the makeup and components (architecture) of the proposed learning model. This section provides an insight into the inner working of the model and how it functions. A number of questions are then identified which need to be explored in practice, and the paper concludes with discussion and suggestions for further research work.

\section{Gulf Perspective}

The promise of creating a learning environment in which graduating students are able to apply the theoretical knowledge learnt in practice and the ability to solve problems and make decisions is a challenge which many higher education colleges in the Gulf region aspire to, work towards and invest in. The model proposed in this paper offers an opportunity; adopting the model should help to align the output of these colleges with the type of work force demanded by regional businesses and service industries. 


\section{Definition}

The model's primary objective is to support the creation of an effective learning environment for higher education programs and modules as depicted in figure 1. An effective learning environment is one which has the following attributes: (a) it provides an engaging and motivating learning experience, which offers the potential for higher knowledge and attendance retention; (b) it develops the student's analysis skills and their abilities to solve problems and make decision and (c) it balances the delivery of theoretical knowledge with its practical application.

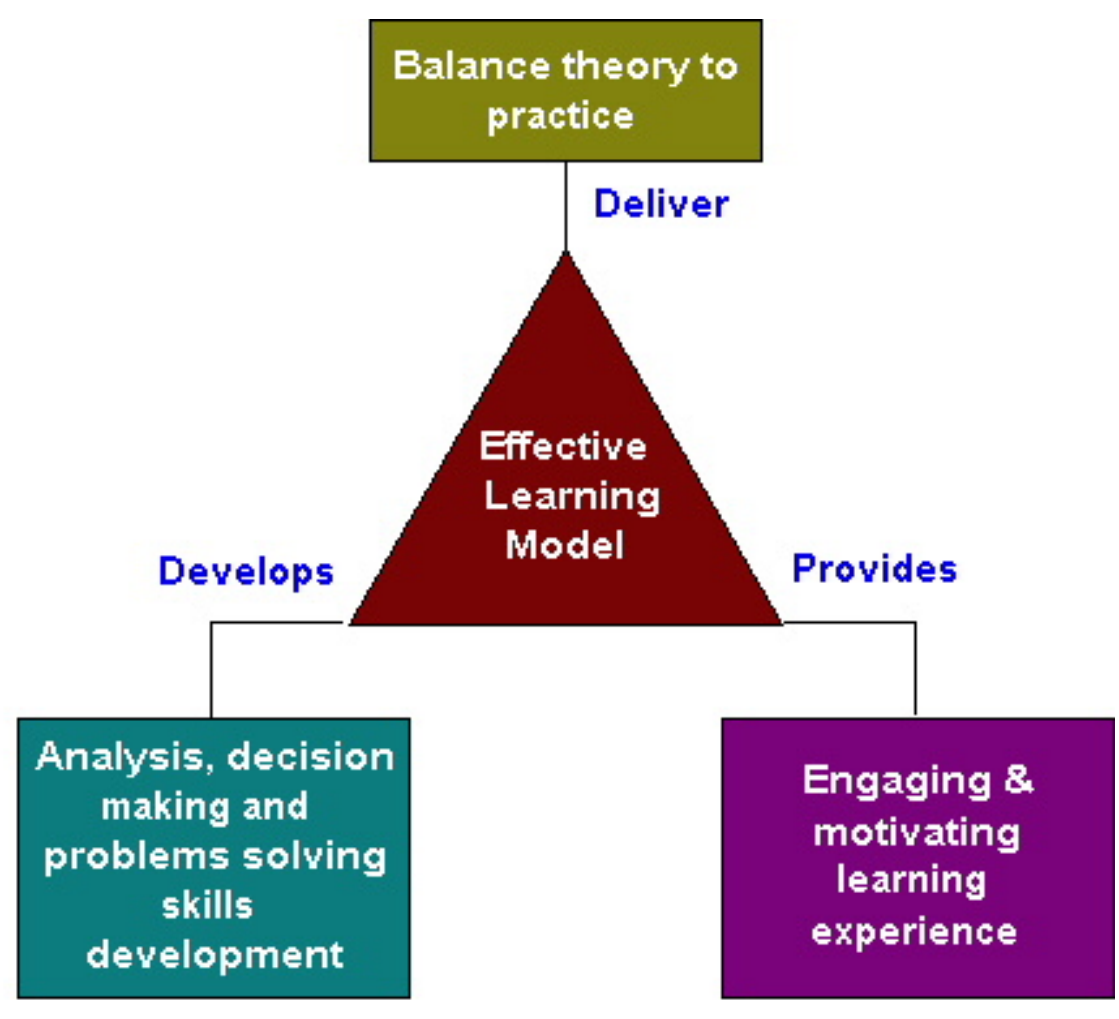

The information technology based instructional model for effective learning attributes

Developed by Dr. Ali H Higgi

Figure 1

\section{Concepts from the Literature}

The most effective learning environments are those that are problem-based and involve the student in four distinct phases of learning: (1) activation of prior experience, (2) demonstration of skills, (3) application of skills and (4) integration of these skills into real world activities (Merrill, 2001). According to Merrill, many instructional practices concentrate primarily on phase 2 and ignore the other phases of this cycle of learning. 
Social interaction and collaboration are two attributes which support effective learning (Agostinho et al., 1997). Social interaction plays an important part in the learning process and can have a significant impact on learning outcome; collaboration is an essential ingredient in the recipe to create an effective learning environment. Collaborative learning fosters the development of critical thinking and is effective in gaining factual knowledge (Gokhale, 1995). Gokhale also concluded that individual learning is as effective as collaborative learning when it comes to gaining factual knowledge, but that collaborative learning is more beneficial if the purpose of the instruction is to enhance critical thinking and problemsolving skills.

Instructional strategies are tools available to educators for designing and facilitating learning. Instructional strategies which are effectively used in traditional classroom and can be used in the online learning environment include: learning contracts, lectures, discussions, self-directed learning, mentorship, small group work, projects, collaborative learning, case studies and forums (Illinois Online Network, 1998-2006).

\section{Problem-Based Learning (PBL)}

With problem-based learning the students work in small groups and are typically presented with complex real world problems structured in such a way that there is no one specific correct answer (Gurrie, 2003). In order to understand the problem and make the necessary decisions required to solve it, the students need to identify the areas of the problem which they understand and research those areas which they do not, and then develop a solution to the problem. In contrast to prevalent teaching strategies in which the concepts are delivered in lecture format and the problems come at the end of the chapter, with PBL the problems come first (White, 1996). In PBL, the teacher or the instructor role is one of a coach, a consultant or subject expert (Gurrie 2003).

Enthusiasm for PBL must be balanced against the challenges that accompany the adoption of such a teaching strategy, particularly for those who are adopting it for the first time. Would-be adopters need to be aware of the potential issues that they may encounter with PBL which they may not encounter when using a traditional in-class, lecture-based teaching model (White, 1996). A common criticism of problembased learning is that less subject matter may be covered with PBL when compared with the traditional, lecture reading and discussion learning model (Gurrie, 2003).

\section{The Proposed Model Architecture (Makeup and Components)}

The proposed model is centered on the traditional in-class learning model, which focuses on five common teaching strategies. These are: in-class lectures, case studies, projects, assignments and problems. This is illustrated in Figure 2 below. 


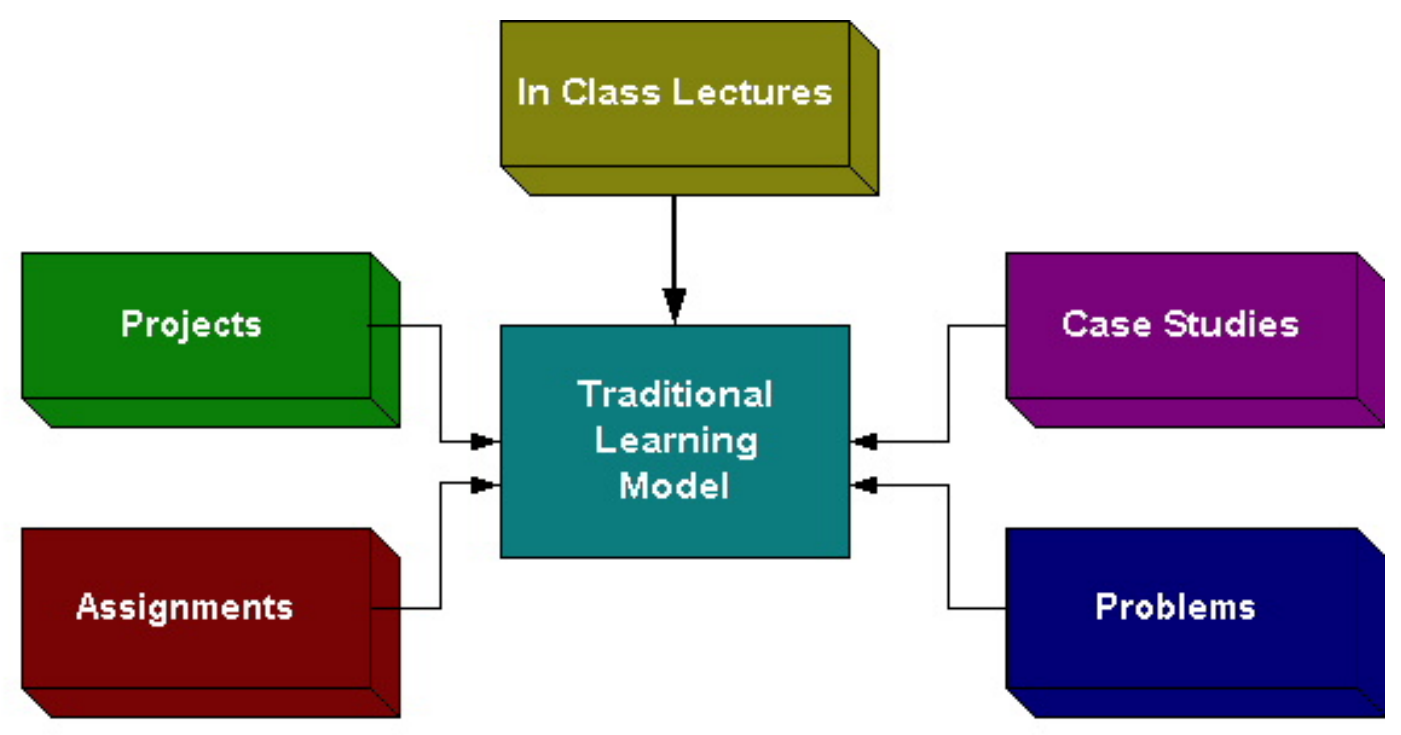

Figure 2: traditional in-class learning model.

The model adopts an innovative approach which provides the basis for creating an effective learning environment as outlined in the definition section above. The approach involves targeting individual instructional strategies with a combination of information technologies and effective learning techniques as depicted in figure 3 below. 


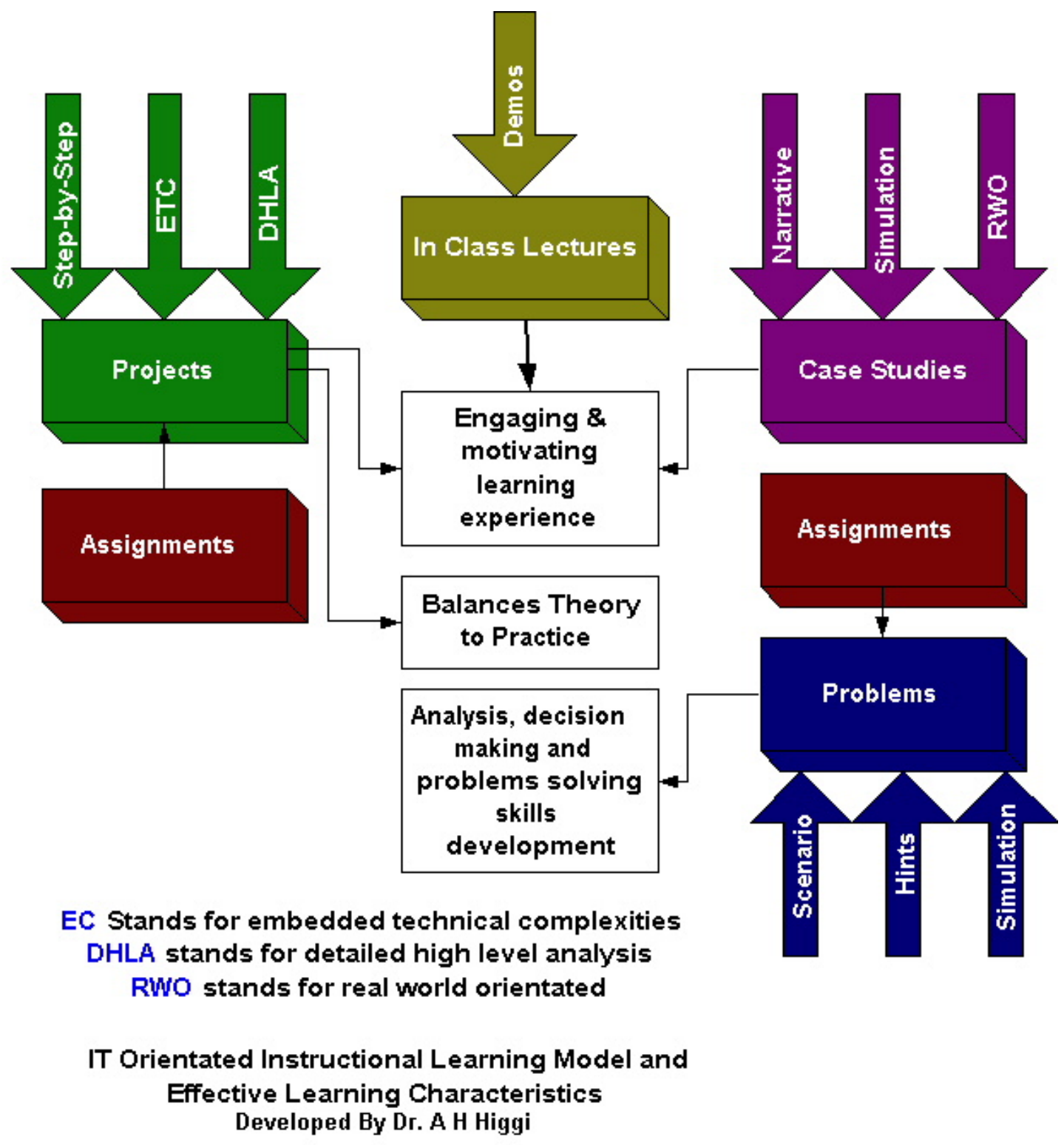

Figure 3: IT-oriented instructional learning model.

The model proposes the delivery sequence shown in figure 4 below in order to create an effective learning environment. However, individual instructors may opt to select alternative sequences which may not include all of the five teaching strategies. The latter option may not result in the creation of an effective learning environment as discussed within the context of this paper. For example, opting to use the in class lectures and case studies only and as prescribed in the proposed model, would deliver only one attribute of the effective learning environment, that is, creating an engaging and motivating learning experience. 


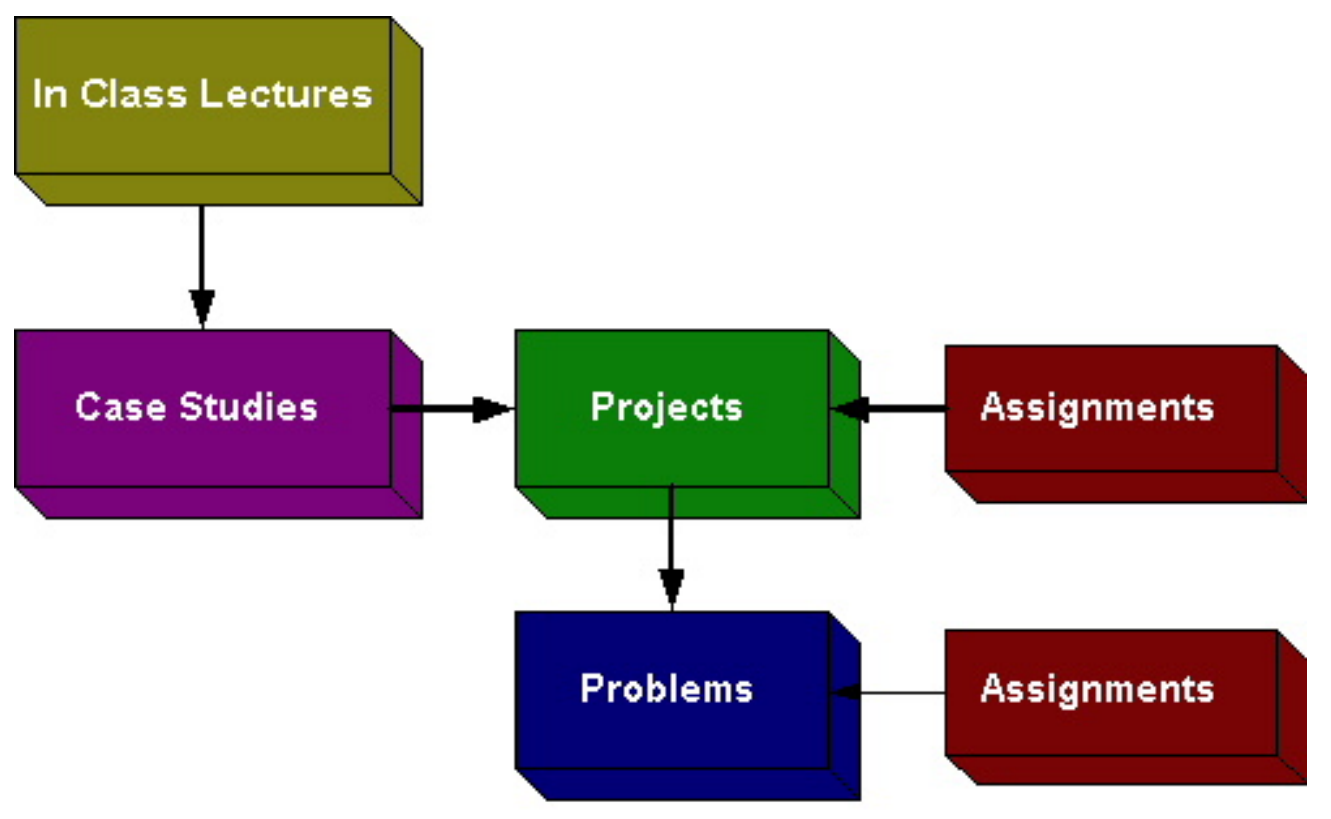

\section{Effective learning Sequence \\ Developed by Dr. A. H Higgi}

Figure 4: Effective learning model.

\section{Further Analysis and Discussion}

Within the context of the in class lectures as an instructional strategy, the proposed model employs the technology in order to go beyond making lectures more appealing through improved presentation and effective graphics. It deploys information technology in order to help clarify complex theoretical concepts through simplified interactive demonstration. Such use of the technology should help to make the lectures not only engaging but also more effective in terms of learning and understanding of the concepts being presented.

Case Studies as an instructional strategy have been used effectively for a long time (Harvard Business School; Wikipedia), and there are plenty of books and articles which provide guidance for writing good and effective case studies ( Higher Education Academy). Typically case studies are real world ones. In order to consolidate understanding of key learning concepts or themes, provide a greater depth on such understanding and deliver on the model's effective and engaging learning experience attribute, the proposed model advocates the use of real world orientated case studies (see below) structured in a narrative-like format. It further advocates the deployment of information technology in order to simulate the key concept being addressed by the case.

Real world case studies are typically proprietary in nature, which often limits the scope of their discussions to aspects that do not interfere with that dimension. For example, if the real case presents 
an information systems solution related to a specific real world organization, the case is not likely to provide an in-depth details relating to: (a) what the solution is, (b) how it works, (c) its architecture and (d) how its data is structured. Furthermore, it will not provide a simple practical feel of the solution through simulating it. The discussion is more likely to be limited to the organizational aspects of the solution such as who created it, the benefits it brought, the lessons learnt and so forth. As a result real world case studies often provide a limited learning experience.

Real world orientated case studies, on the other hand, are typically created by their authors, based on real business problems, but are not based on a specific real world organizations and present generic solutions. These attributes enable the case's creator to present a case with the depth necessary to provide a richer learning experience. For a case study example with information technology simulation support, browse to Higgi (2007) and follow the link for Effective learning mode/lCase study.

Typically projects as learning methodology follow a "sink or swim" strategy; that is, the project's deliverables are identified by the project's creator and then it is left to the student to carry out all that is necessary in order to complete the project. This task may involve identifying all the knowledge and tools required for a successful project completion.

The model proposed here instead follows a "learn to swim" strategy. It offers the potential that an assigned project is successfully completed by every participating student: it does not limit successful completion to those students who are naturally motivated, knowledgeable and engaged in the learning process. It fosters an environment whereby the student's sense of achievement is cultivated in order to enhance his or her motivation and engagement in the learning process and hence realize the learning objectives which are set to be achieved by the projects.

In order to deliver on this potential, the proposed model advocates a four-step project completion process. It includes: (a) step-by-step guidance; (b) embedded technical complexities; (c) detailed high level analysis and (d) assignments. The step-by-step part guides the students through all the steps required in order to complete the project unhindered. Complex elements of the projects are developed by the project's creator using information technology in order to hide all the technical complexities which are associated with the project. In order to help understand and appreciate the project's embedded technical complexities, a detailed but high level analysis of it is provided for the project performer to examine. Assignments play a critical part in enforcing understanding of the overall objectives of the project. The philosophy behind the project part of the proposed model is best illustrated with the help of an example which can be found by browsing to Higgi (2007) and then following the link Effective learning mode/Projects.

Problems are the element of the proposed model which helps the students to build their analysis skills and develop their abilities to solve problems and make decisions. A 4 step methodology is followed in order to realize these learning attributes. These steps are: (1) structuring the problems in a real-world 
orientated, scenario-like format; (2) complementing them with hints; (3) deploying information technology; and (4) supporting the problems with assignments.

With the proposed model, the problems are part of a lecture centered learning process and would typically come at the end of the lecture or lectures assigned to a particular topic or a learning theme. Fundamentally, most of the knowledge that would be required in order to solve the problem would have been covered in the associated lectures. The following discussions will further analyze the four components cited earlier.

A key characteristic of the problems is that they are real world orientated and would typically be created in a scenario like format. An example of this is as follows:

While inspecting the sales reports for the just ended 1st quarter, the sales director concluded that the quarter's sales are $20 \%$ less than that which was forecasted for that quarter. A closer analysis of the sales data revealed that key items were not selling as expected. The sales director concluded that should the trend continue the business's end of year forecasted revenue and profits will not match expectation...

The associated assignment would typically consist of questions which force the student to think, analyze and decide as part of the process of solving the problem in question. In order to help with this process, the student would be provided with limited but general high level hints. These hints would typically act as a guiding post to developing the solution. An example of a possible assignment that may be used with the problem which is described in the above scenario would be as follows:

Imagine that you are the sales director of Business A and you are faced with the above cited problem. Your task is to propose a potential solution or solutions and be prepared to present them to your management and argue the case for their merits and approval.

Possible potential hints that may be suitable as part of such an assignment may be of the following nature:

a. Identify 3 to 4 possible but varied promotional strategies. An example of such strategy is to buy one get the second one at half price.

b. Use the associated problem's simulation system in order to evaluate each one of the promotional strategies. Analyze how revenues, profit margins, sales, etc... may be affected by each strategy.

As it is of critical importance to help the student gain more understanding and develop a better insight into the problem, the problem's general behaviors are simulated using information technology.

In order for the problems element part of the proposed model to succeed in delivering its primary goals building the students analysis, problem-solving and decision-making skills - all of the 4 steps cited earlier have to be implemented collectively. That is, the problem element must be created in a real-world oriented scenario format, complemented with hints, supported with assignments and the problem 
behaviors simulated using information technologies. Visit Higgi (2007) in order to see an example which enhances your appreciation of the above discussion.

\section{The role of Information Technology}

As illustrated in figure 2, information technology (IT) has a critical role to play in delivering the model's overall objectives. IT is used in order to develop the programming modules which simulate case studies solutions and problems behaviors. Furthermore, information technologies are used in order to build the programs modules which are needed in order to hide all of the technical complexities associated with the projects. In addition IT provides the interactive demos required to enhance the in-class lectures. It is reasonable to argue that without information technology support this model would not work.

\section{Questions to explore in practice}

How to enhance the undergraduate traditional lecturer centered learning model so that the learning environment is one which supports the following attributes:

High level of student motivation in the process of learning.

Quality student engagement in the learning process.

Student engagement at an individual level (not only at a group level), with due regard to the individual student's capabilities; that is, to engage students of all levels of academic ability and not just the most academic ones.

High in-class attendance level and successful completion of assignments and projects.

An enhanced learning experience through creating a positive learning atmosphere.

Create the appropriate balance between theory and practice with a greater emphasis to real world relevance

\section{Discussion and research questions}

The model was initially developed in order to support the author's courses in management information systems (MIS), which is why all of the cited examples are MIS orientated. However, due to its robust and flexible nature, the model design lends itself readily to being adopted by other higher education disciplines. Further research work is suggested in order to examine this opportunity further.

Simulation using information technology is a central element of the proposed model. It is reasonable to argue that higher education faculty and lecturers may well not possess the required specialized technical and computing skills in order to develop the required simulation. The author expects that this gap will be addressed through appropriate collaboration between various educational departments and their school of information technology. Alternatively, it may be created by third party material and resources 
developers such as higher educational publishers. The author's own website cited in this paper (Higgi, 2007 ) is an example of the latter approach for simulation development.

It is suggested that further research work may be carried out in the following areas: (a) advanced assessment; (b) comparison; (c) adaptability; (d) technology.

Advanced Assessment: Investigation would be needed in order to determine the true position of the proposed model as an effective learning environment. This would involve developing a more scientific and rigorous evaluation methodology. The methodology will need to generate comparative data and be practical in nature and wide in scope.

Comparison: Work would need to be undertaken in order to determine how effective the proposed model is when compared with other effective learning environments such as problem based learning and collaborative learning.

Adaptability: Research work could be carried out in order to determine the applicability of the proposed model in other educational undergraduate social science programs such as finance, marketing, management, etc... The work may involve evaluating the suitability of the model as a whole or in part.

Technology: Research work could be undertaken in order to evaluate the feasibility, applicability, ease of use, accessibility and effectiveness of various information technology platforms which may be used in order to develop the required model's simulation as well as being used as a development platform for the projects. Comparative data may be generated and analyzed.

\section{References}

Agostinho, S., Lefoe, G. and Hedberg, J. (1997). Online Collaboration for Learning: A Case Study of a Post Graduate University Course. Third Australian World Wide Web Conference. 5-9 July 1997, Southern Cross University, Australia. Accessed 27 February 2007 at http://ausweb.scu.edu.au/proceedings/agostinho/paper.html.

Gokhale, A. (Fall 1995). Collaborative Learning Enhances Critical Thinking. Journal of Technology Education 7(1). http://scholar.lib.vt.edu/ejournals/JTE/v7n1/gokhale.jte-v7n1.html.

Gurrie, J. (2003). What's Your Problem? Increasing Student Motivation and Quality of Participation in Discussions through Problem-Based Learning. Elearnspace. http://www.elearnspace.org/Articles/contributor/pbl.htm.

Harvard Business School. Making a Case: The Birth of an HBS Case Study. Enterprise Newsletter. http://www.hbs.edu/corporate/enterprise/case.html.

Higgi, A.H. (2007). Hala Education. http://www.halaeducation.com/

Illinois Online Network (1998-2006). Instructional Strategies for Online Courses.

http://www.ion.uillinois.edu/resources/tutorials/pedagogy/instructionalstrategies.asp

Higgi, A.H. (2007). An Information Technology Based Instructional Model for Effective Learning. Learning and Teaching in Higher Education: Gulf Perspectives, 4(1). http://www.zu.ac.ae/lthe/lthe04_01_04_higgi.htm 
Merrill, M. D. (2002). First principles of instruction. Educational Technology Research and Development, 50(3), 43-59.

Higher Education Academy, Handbook for Economics Lecturers. What makes a good case study? http://www.economicsnetwork.ac.uk/handbook/casestudies/34.htm

White, H. B. (1996). Dan Tries Problem-Based Learning: A Case Study. In L. Richlin (Ed.). To Improve the Academy 15 (pp. 75 - 91). Stillwater, OK: New Forums Press and the Professional and Organizational Network in Higher Education. http://www.udel.edu/pbl/dancase3.html.

Wikipedia. Case study. http://en.wikipedia.org/wiki/Case study.

\section{Author}

Dr. Ali Hussain Higgi holds a PhD from the University of Wales, UK. His current employment portfolio includes part-time lecturing as a professor of Information Technology and Business Systems and working as an IT consultant to business. Author of Information Systems And Management In Business (November 2007) - an undergraduate book aimed at business students majoring in business or management information systems. Email: ah@halaeducation.com 